\title{
Strategies for Communicating Health and Safety Information on Construction Sites in Nigeria
}

\author{
Samuel Abiodun Alara \\ samuelabiodunalara@fpmubieportal.edu.ng \\ Federal Polytechnic Mubi, Adamawa, Nigeria \\ Ibrahim Ibrahim Inuwa \\ iiinuwa@atbu.edu.ng \\ Abubakar Tafawa Balewa University, Bauchi, Nigeria
}

\begin{abstract}
The construction industry $(\mathrm{CI})$ has earned the notoriety of being a risky or profoundly unsafe industry. Studies have credited the majority of the mishap on construction sites to poor communication of health and safety (H\&S) information among all the parties engaged in construction activities. The study assessed strategies for communicating $\mathrm{H} \& \mathrm{~S}$ information on construction sites and evaluates factors influencing the choice of communication strategies for H\&S information on construction sites. The data for the investigation were gotten using multiple-choice questionnaire administered on 20 construction sites domicile in Abuja, Nigeria. A sum of one hundred (100) questionnaire were administered to respondents; out of which eighty-five (85) were returned speaking to $85 \%$ reaction rate. Data received were analyzed using descriptive and inferential statistics at $95 \%$ degree of certainty. The study revealed that safety signs and training are most important medium of communicating H\&S information on construction sites and shown that cost implication of the strategy significantly influences the choice of communication strategies for H\&S information on Nigerian construction sites. The study therefore, recommends that contracting firms be duty-bound to engage signs and symbols in communicating $H \& S$ information, as communication that involves images is clearer and can be directly understood. Quantity surveyors should ensure that adequate provision is made in the bill of quantities for implementing H\&S procedures on construction sites. Safety awareness ought to be incorporated in the overall procurement procedure, and workers should be consistently train and re-train on H\&S procedures.
\end{abstract}

Keywords: Semiotics; Health and safety information; Communication strategies; Nigeria

\section{INTRODUCTION}

The construction industry $(\mathrm{CI})$ has earned the notoriety of being a risky or profoundly unsafe industry in light of the fact that it has a poor health and safety $(\mathrm{H} \& \mathrm{~S})$ execution record, with operatives' multiple times bound to experience the ill effects of deadly wounds than those in different sectors everywhere throughout the world (Alhajeri, 2011; Dadzie, 2013; Phoya, 2012). The International Labor Organization (ILO) appraises that in any event 60,000 lethal mishaps occur annually on building sites around the globe, which is one out of six of all deadly construction related mishaps. Besides, it has 
been recognized that $25-40 \%$ of fatalities on the global workplace related accidents are contributed by construction (International Labor Organization-ILO, 2017).

Several studies led in developed and developing nations corroborate proof of this generally high extent of mishaps on building sites. In Australia, the CI comprises $9 \%$ of absolute workforce, yet records a casualty rate double that of other sector, and compensate $11 \%$ of every single genuine laborer's remuneration claims (Greuter et al., 2012). In Europe, the CI records $30 \%$ of all lethal mechanical mishaps, notwithstanding utilizing just $10 \%$ of the working populace (McKenzie et al., 1999). According to BLS (2016) report; in United State of America, fatality rate expanded to 10.1 for every 100,000 full-time comparable (FTC) in 2015 as against 9.8 for every 100,000 (FTC) in 2014. In Saudi Arabia, the CI represents 51.35\% out of 69,241 all the mishaps cases documented (General Organization for Social Insurance (GOSI), 2015). In Japan, construction casualties represent $30 \%-40 \%$ of the overall aggregate of contemporary mishaps, with the absolute being half in Ireland (ILO, 2017). It was likewise affirmed that construction lethal mishaps represent $59 \%$ of absolute deadly mishaps in all sectors all over Singapore. In Italy, the deadly mishaps in the CI speak to $25 \%$ of the absolute mishaps happening in the sector (Baldacconi \& Santis, 2000). In Ghana, it was accounted for that the CI recorded 902 mishap cases containing 56 lethal mishaps and 846 non-deadly mishaps in year 2000 (Danso, 2005). In that equivalent report, it was demonstrated that Kumasi (the provincial capital of Ashanti) alone documented 124 construction mishap from 1999 to 2004. Besides, Laryea and Mensah (2010) uncovered a poor condition of H\&S on Ghanaian CI. In Nigeria, the CI is liable for about $7.5 \%$ of all work related mishap, $49.5 \%$ of these incidents were deadly, $12.2 \%$ of fractional handicaps and $7.4 \%$ of minor wounds (Umeokafor et al., 2014). The Nigerian CI losses $5-7 \%$ of her labor force every year to construction mishaps (Olatunji et al., 2007). As indicated by Abdullahi et al. (2015), $76.40 \%$ of site operatives in Nigeria had one type of mishaps or the other on building sites.

The issues of mishaps and ill health problems in building and CI are of serious concern globally (Alhajeri, 2011; Dadzie, 2013; Phoya, 2012). Thus several researches have been conducted across the globe to improve on H\&S status on construction (Albert et al., 2014; Danso, 2005; Greuter et al., 2012; Hare et al., 2012; Inuwa et al., 2018). Findings from studies carried out to assess the causes of accidents have all pointed to poor communication of $H \& S$ information among all the parties engaged in construction activities (Akunyumu, 2017; Kwofie, 2015; Landin \& Kindahl, 2013). Albert et al. (2014) discovered that communication is the paramount strategy for risks identification. Communication of H\&S has been regarded to be a pivotal point for decreasing mishaps and ill-health complications on construction sites and crucial to attaining acceptable level of efficient and effective H\&S on construction sites (Phoya, 2012).

However, in Nigeria, communication on construction sites has been inadequate and declined to worrisome state, over $50 \%$ of construction projects in Nigeria failed because of unsuitable communication strategies (Kasimu \& Usman, 2013). Besides, for H\&S information to be compelling it must be comprehended, which is governed by the strategy utilized (Preece \& Stocking, 1999; Vecchio-Sadus, 2007). With expanded budgetary ramifications associated with construction related injuries and the rising quest for zero incident undertakings, researchers are investigating the execution of inventive 
H\&S communication strategies (Albert et al., 2014; Greuter et al., 2012); including signs and images as a communication strategy (Ogunmola, 2013). However, semiotics; the science underpinning how signs and images are utilized to pass information, is a domain that is yet to be appropriately investigated to reduce mishaps on building sites (Inuwa et al., 2018).

An audit of studies led on communication on building sites in the Nigerian CI fall short of focusing on how semiotics can be utilized to facilitate effective H\&S communication on construction site (Olaniran, 2015; Tipili \& Ojeba, 2014). Thus this research investigated how semiotics can be utilised to enhance effective H\&S communication on construction sites in Nigeria, with the end goal of enhancing H\&S management that will diminish the event of mishaps on construction sites. The investigation sketched out the following objectives: to assess strategies for communicating H\&S information on construction sites, to evaluate factors influencing the choice of strategies for effective H\&S communication on construction sites.

\section{LITERATURE REVIEW}

\subsection{Theoretical construct}

This investigation builds on the theory of semiotics as upheld by Charles Sanders Peirce (1839-1914). Semiotics is the umbrella term used to depict the theory or investigation of signs and images as methods for communication. As indicated by Huhtamo (2003), semiotic is a field of study that reviews signs as a fundamental piece of social life and communication; semioticians certify that, we can just know culture (and reality) by methods for signs, through the procedures of signification. Signs incorporate words, signals, pictures, sounds, and articles (Henley et al., 2015). For example, the manner by which the individuals who are hard of hearing convey utilizing communication through sign language shows how people react to semiotics and that signs and images can reverberate the same amount of information as words. Undoubtedly, sometimes semiotics transcends language as a means of communication. In semiotics, the word sign has uncommon importance; for example, side effect is an indication of ailment in a wiped out individual. Thus sign is something which represents something (Crow, 2017). Peirce hypothesis of semiotics hypothesized that a sign can possibly successfully convey a message if the intended interest group for which the message is aimed at comprehends the interrelationship between representamen (signifier), interpretant (signified), and the object inside the setting of a sign (Berger, 2004; Crow, 2017).

Along these lines for a sign to be compelling in imparting a message to an individual (subject) inside the setting of construction industry culture, the individual must: perceive the structure the sign takes (signifier; representamen), comprehends (interpretant) the message the signifier is passing on (connoted; appreciation), and recognize the thought wherein the sign represents; the motivation behind the sign (Object).

\subsection{Conceptual Framework}

Semiotics in built environment can radically improve the capability of H\&S communication strategies and help guarantee that different and more extensive audience can be reached adequately. However, it will take consistent implementation for strategy to establish a clear semiotic association and image will help speed up this process, as 
it facilitates memory recall. Semiotics in safety can thus be achieved through leitmotifs (reoccurring images). In addition, for the workers to comprehend what this H\&S signs represent, they should above all else recollect (Inuwa et al., 2018). Accordingly, this will improve effective communication on construction sites. The workers applying what he has perceived and recognize from different strategies will manage the worker in acting securely on site. Subsequently, empowering the worker to accomplish the objective of the strategy; preventing and curbing accidents on construction sites. This idea is presented in Figure 1.

COMMUNICATING HES INFORMATION ON CONSTRUCTION SITES

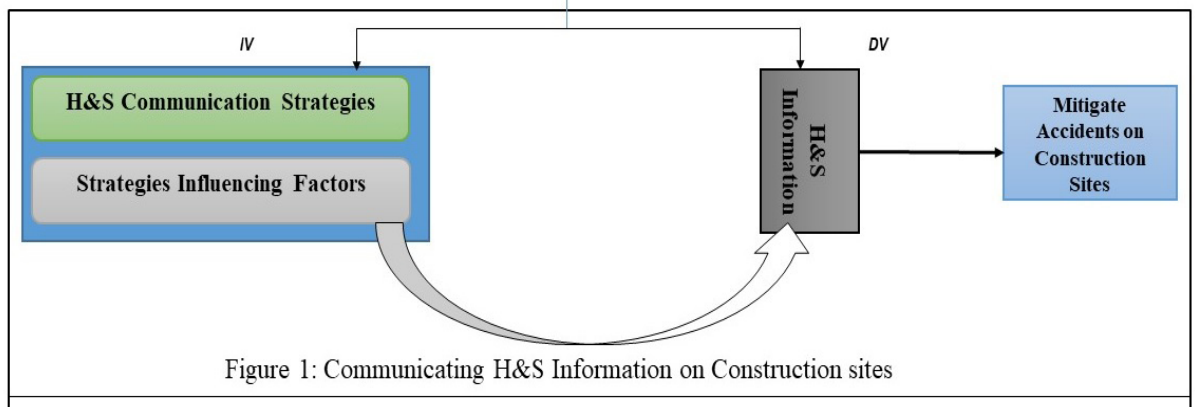

\subsection{Strategies for Communicating Health and Safety Information on Construction sites}

For $\mathrm{H} \& \mathrm{~S}$ communication to be effective it has to be understood, which is governed by kind of information to be communicated, the target audience, environment where transmission takes place and the strategy used (Preece \& Stocking, 1999; VecchioSadus, 2007). The communications strategy of contracting firms; fills in as a suggested structure and activity plan for an association's interchanges and effort endeavors. Studies uncovered that strategies for imparting $H \& S$ information on building sites include organization mission statement, strategic plan and policy, checklists manuals and operating procedures, hazards reports, incidents and near-misses, safety induction, training, H\&S website, posters, brochures and notice boards, H\&S signs, toolbox talks, H\&S week and public report (Preece \& Stocking, 1999; Vecchio-Sadus, 2007). VecchioSadus (2007) in his studies acknowledged that a number of strategies are required for various organization and choosing the viability of communication of $\mathrm{H} \& \mathrm{~S}$ information relies upon the strategy utilized. This strategy will impact whether individuals will comprehend or not and take part in the $\mathrm{H} \& \mathrm{~S}$ procedure. The language utilized frequently decide its adequacy, in bid to enhance $H \& S$ status of workers on building sites, parties involved need to pay attention to the choice of communication strategies to be used on the sites. Recent developments in the CI have shown the need to assess strategies for communicating H\&S information on construction sites in Nigeria for effective $\mathrm{H} \& \mathrm{~S}$ communication on site.

\subsection{Factors Influencing the Choice of Communication Strategies for Health and Safety}

Strategies of communications of $\mathrm{H} \& \mathrm{~S}$ information can take many different forms, 
with each being appropriate for particular circumstances. It is important to first consider the objective of communication i.e. to persuade; inform; question or instruct the workers on health and safety issues (Preece \& Stocking, 1999; Vecchio-Sadus, 2007). This will now be tailored to the strategy that suits the objective of the communication. Studies revealed that choice of communication strategies can be influence by availability of time/ time pressures, literacy skill of site operatives, awareness of information technology, number of recipients, types of information/message, nature of hazard/severity of the risks involved and cost implication of the strategy (Preece \& Stocking, 1999; VecchioSadus, 2007) opined that so as to enhance H\&S status of workers on building sites, parties involved need to pay attention to the choice of communication strategies to be used on the sites. Recent developments in Nigerian CI have led to a renewed interest on the factors influencing the choice of communication strategies for $\mathrm{H} \& \mathrm{~S}$ information in Nigeria. An audit of studies led on H\&S management in Nigeria revealed little or no studies led on factors influencing the choice of communication strategies for $\mathrm{H} \& \mathrm{~S}$ information on construction sites in Nigeria Accordingly, there is a need to evaluate factors influencing the choice of communication strategies for H\&S information on construction sites in Nigeria.

\section{METHODOLOGY}

This study was led in Abuja, the capital of Nigeria; it has the most elevated convergence of construction activities in the nation, and in that capacity has the most elevated centralization of construction experts (Inuwa, 2014). The experience of the experts' transverses the whole nation. Literatures were explored to identify strategies used for communicating H\&S information and factors influencing their choice on construction sites. Afterwards a multi-choice questionnaire was designed to evoke information from respondents on the import of strategies for communicating H\&S information on construction sites and evaluates factors influencing the choice of communication strategies for $\mathrm{H} \& \mathrm{~S}$ information on construction sites respectively. The investigation utilized purposive sampling to choose key respondents from every one of the classes of respondents to guarantee that the correct respondents with the important information, authority and experience on the topic were satisfactorily chosen. The respondents comprised of construction professionals (management staff/safety officers) carefully chosen from contracting firms; engaged with the administration of 20 on-going government building ventures domiciled in Abuja, Nigeria. One hundred structured questionnaire were distributed to respondents and, accomplishes $85 \%$ return rate. This return rate is well satisfactory in the perspective of built environment researchers and sufficient for an important examination (Inuwa, 2014). The study used Cronbach alpha coefficient to test the internal consistency of the questionnaire reliability, the Cronbach's $\alpha$ measure for the questionnaire constructs revealed that the questionnaire is very reliable, since their Cronbach's $\alpha$ exceeds 0.7 (Pallant, 2011). The questionnaire sought information on respondents' profiles. The respondents were solicited to rate the degree of effectiveness of identified strategies in communicating $\mathrm{H} \& \mathrm{~S}$ information and indicate the extent to which variables influences contracting firms in choosing a communication strategy that will be most suitable. Respondents view were depended on a 5-point Likert scales: 5(strongly agree/extremely important), 4(agree/very important), 
3(neutral), 2(disagree/slightly important) and 1(strongly disagree/not at all important). To empirically assess the effectiveness of identified strategies and to give an understanding with regards to the degree to which each factor adds to conveying H\&S information on construction sites in Nigeria; the Relative Importance Index (RII) was utilized. It is a non-parametric statistical technique largely employed by built environment scientists for investigating organized survey reactions for information including ordinal estimation of frames of mind (Kometa et al., 1994). RII was employed for the examination as it is apt for the motivation behind this investigation. In the estimation of the Relative Importance Index (RII), the formula beneath was utilized (see equation underneath):

$$
\mathrm{RII}=\sum \frac{\mathrm{W}}{\mathrm{AN}} * 100
$$

Where $\mathbf{W}$ is the weighting given to each item by the respondents range from 1 to 5 ; i.e. 5 for highest to 1 for lowest while ' $n$ ' is the number for respondents for each weighting. $\mathbf{A}$ is the highest weight; $\mathbf{N}$ is the total number of the respondents. RII esteem ranges from $(0 \leq \mathrm{RII} \leq 1)$. It indicates that higher the estimation of RII, increasingly significant was the communication strategy and vice versa, also the higher the estimation of RII, progressively powerful was the factor in the choice of most suitable communication strategies for $\mathrm{H} \& \mathrm{~S}$ information and the other way around. The correlation of RII with the comparing significance level is estimated as per the following range:

From 0.8 to 1.0 adjudged High $(\mathrm{H})$, from 0.6 to $<0.8$ adjudged High-Medium $(\mathrm{H}-\mathrm{M})$, from 0.4 to $<0.6$ adjudged Medium (M), from 0.2 to $<0.4$ adjudged Medium-Low (M$\mathrm{L}$ ), while 0.0 to $<0.2$ is adjudged Low (L).

\section{RESULTS AND DISCUSSION}

\subsection{Respondents Demographic Profiles}

The significance of statistic data cannot be undermined for an important quantitative investigation. During the research, respondents were requested to provide generation information. As the point of research is centered around the construction stage of the projects, so it was conceived to choose key respondents from every one of the classes of respondents to guarantee that the correct respondents having acceptable expert experience were satisfactorily chosen. Analysis of the feedbacks shows that well over $98 \%$ of the participants are within the range of 31 to 35 years and over 50 years of age. This indicates that the vast majority of the participants are sufficiently aged to be safety mindful. Likewise, $93 \%$ of the feedbacks are male whereas the residuals are female. This portrays the idea of the CI as male ruled industry. The result of the feedback indicates that over $98 \%$ of the respondents have finished their bachelor degree or advanced education. Above $63 \%$ of the respondents are project managers, over $8 \%$ are architects, over $23 \%$ are safety officers, while $4.7 \%$ are engineers. This outcome uncovered that these classes of participants are the one's generally engaged with H\&S management on construction sites. The participants have more than 15 years' field involvement with the CI. The participants have a mean sum of over 22 years work involvement with the CI. This shows the participants have satisfactory work involvement with the CI, to react to the investigation of this nature. 


\subsection{H\&S Communication Strategies}

The first objective was to assess strategies for communicating H\&S information on construction sites in Nigeria. The following H\&S communication strategies; safety signs and training, organization mission statement, policy and strategic plan, safety induction and toolbox talks, safety week and public report, manuals, checklists and operating procedures, reports of hazards and brochures as well as health and safety website were ranked first, second, third, fourth, fifth, sixth and seventh position respectively. Table 1 summarize the Relative Importance Index (RII) of the communication strategies alongside their equivalent ranking and significance level. It is apparent from Table 1 that ten techniques were evaluated as "High significance levels which are adjudged as of prime significance in conveying H\&S information on construction sites while website was ranked as "high medium significance level". These "High" significance markers have Relative Index (RII) in the scope of 0.95-0.85. These high ranked strategies include health and safety signs $(\mathrm{RII}=0.95)$, training $(\mathrm{RII}=0.95)$, organization mission statement, policy and strategic plan $(\mathrm{RII}=0.91)$, safety induction $(\mathrm{RII}=0.89)$, toolbox talk $(\mathrm{RII}=0.89)$, health and safety week $(\mathrm{RII}=0.88)$, public report $(\mathrm{RII}=0.88)$, manuals, checklists and operating procedures $(\mathrm{RII}=0.87)$, reports of hazards, incidents and nearmisses $(\mathrm{RII}=0.85)$, brochures, posters and notice boards $(\mathrm{RII}=0.85)$ and health and safety website $(\mathrm{RII}=0.74)$. They are considered by respondent as important medium of communicating H\&S information on construction sites.

The study revealed that safety signs and training are most important medium of communicating $\mathrm{H} \& \mathrm{~S}$ information on construction sites with an aggregated relative importance index of 0.95 and was ranked as the top most strategies for communicating H\&S information on construction sites in Nigeria, which is in agreement with studies by (Hare et al., 2012) and (Md-Ulang, 2012) however, these studies were conducted in The United Kingdom respectively.

Table 1: Relative Importance Index (RII) of the Communication Strategies

\begin{tabular}{|l|c|c|c|c|c|}
\hline H\&S Communication Strategies & N & Mean & RII & Level & Ranking \\
\hline Organization Mission Statement, Policy and Strategic Plan & 85 & 4.55 & 0.91 & hH & 2nd \\
\hline Safety Induction & 85 & 4.45 & 0.89 & H & 3rd \\
\hline Manuals, Checklists and Operating procedures & 85 & 4.33 & 0.87 & H & 5th \\
\hline Reports of Hazards, Incidents and Near-Misses & 85 & 4.27 & 0.85 & H & 6th \\
\hline Training & 85 & 4.73 & 0.95 & H & 1st \\
\hline Health and Safety Website & 85 & 3.69 & 0.74 & H-M & 7th \\
\hline Brochures, Posters and Notice Boards & 85 & 4.25 & 0.85 & H & 6th \\
\hline Health and Safety Warning Signs & 85 & 4.73 & 0.95 & H & 1st \\
\hline Toolbox Talks & 85 & 4.45 & 0.89 & H & 3rd \\
\hline Health and Safety Week & 85 & 4.38 & 0.88 & H & 4th \\
\hline Public Report & 85 & 4.39 & 0.88 & H & 4th \\
\hline
\end{tabular}

\subsection{Factors Influencing Choice of Strategies}

Table 2 shows the Relative Importance Index (RII) of factors influencing the choice of communication strategies for H\&S information alongside their equivalent ranking and 
significance level. From the summary of results in Table 2, it can be observed that all the factors were rated as "High importance levels which are adjudged of prime importance in the choice of communication strategies for H\&S information on construction sites in Nigeria. These "High" significance pointers have Relative Index (RII) in the scope of $0.99-0.81$. These high ranked factors include cost implication of the strategy $(\mathrm{RII}=0.99)$, availability of time/time pressures $(\mathrm{RII}=0.88)$, literacy skill of site operatives $(\mathrm{RII}=0.85)$, awareness of information technology $(\mathrm{RII}=0.85)$, nature of hazard/severity of the risks involved (RII $=0.85)$, types of information/message $(\mathrm{RII}=0.84)$ and number of recipients $(\mathrm{RII}=0.81)$. They are considered by respondent as important factors in the choice of communication strategies for $\mathrm{H} \& \mathrm{~S}$ information on construction sites. Similarly, the investigation revealed that cost implication significantly influences the choice of communication strategies for H\&S information with an aggregated relative importance index of 0.99 and was rated as the top most factor that influence the choice of communication strategies for $\mathrm{H} \& \mathrm{~S}$ information on construction sites in Nigeria which is in agreement with studies by Windapo (2013), however, this study was led in Western Cape region of South Africa.

Table 2: Factors that influence the choice of communication strategy

\begin{tabular}{|l|c|c|c|c|c|}
\hline H\&S Communication Strategies & N & Mean & RII & Level & Ranking \\
\hline Availability of Time/Time pressures & 85 & 4.41 & 0.88 & $\mathrm{H}$ & 2nd \\
\hline Literacy Skill of Site Operatives & 85 & 4.27 & 0.85 & $\mathrm{H}$ & 3rd \\
\hline Awareness of Information Technology & 85 & 4.27 & 0.85 & $\mathrm{H}$ & 3rd \\
\hline Number of Recipients & 85 & 4.05 & 0.81 & $\mathrm{H}$ & 5th \\
\hline Types of Information/Message & 85 & 4.20 & 0.84 & $\mathrm{H}$ & 4th \\
\hline Nature of hazard/severity of the risks involved & 85 & 4.26 & 0.85 & $\mathrm{H}$ & 3rd \\
\hline Cost Implication of the Strategy & $\mathbf{8 5}$ & 4.93 & 0.99 & $\mathrm{H}$ & 1st \\
\hline
\end{tabular}

\section{CONCLUSION}

The study revealed that safety signs and training are most important medium of communicating H\&S information on construction sites which imply that contracting firms ought to engage signs and symbols in communicating H\&S Information and continuously train construction operatives on $\mathrm{H} \& \mathrm{~S}$ signs and symbols assimilation. Similarly, the study also revealed that cost implication significantly influences the choice of communication strategies for H\&S information which implies that contracting firms may not implement H\&S communication strategy, if the cost of strategy is a lot when contrasted with their expected profit margin. The study therefore, recommends that contracting firms H\&S communication strategy be considered as one of the grounds for awarding contract and ensure strict compliance, as adherence will definitely maximize safety performance of our construction sites. Contracting firms be duty-bound to engage signs and symbols in communicating $\mathrm{H} \& \mathrm{~S}$ information, as communication that involves images is clearer and can be directly understood. Quantity surveyors should ensure that adequate provision is made in the Bill of Quantities for health and safety management on construction sites. Safety awareness ought to be incorporated in the overall procurement procedure, and workers should be consistently train and re-train on $\mathrm{H} \& \mathrm{~S}$ procedures. 


\section{REFERENCES}

Abdullahi, U., Anum, I., Adole, A. M. \& Williams, F. N. (2015). Artisans Working Conditions In The Nigerian Construction Industry: A Case Study Of Some States In Northern Nigeria. ATBU Journal of Environmental Technology (A'JET), 8(1), 16-25.

Akunyumu, S. (2017). A framework for on-site communication planning for construction managers in Ghana. (Master of Philosophy Thesis), College of Art and Built Environment, KNUST, Kumasi, Ghana.

Albert, A., Hallowell, M. R. \& Kleiner, B. M. (2014). Emerging Strategies for Construction Safety \& Health Hazard Recognition. Journal of Safety, Health \& Environmental Research, $10(2), 152-161$.

Alhajeri, M. (2011). Health and Safety in the Construction Industry: Challenges and Solutions in the UAE. Coventry University, Coventry.

Baldacconi, A. \& Santis, P. (2000). Risk assessment in construction field in Italy. Rome, Italy: National Institute for Insurance against injuries at Work.

Berger, A. A. (2004). Techniques Of Interpretation: Semiotic Analysis Media Analysis Techniques. SAGE Publications, Incorporated.

BLS (2016). National Census Of Fatal Occupational Injuries In 2015. United States of America: Bureau Of Labor Statistics.

Crow, D. (2017). Visible Signs: Intro to Semiotics From David Crow's Visible Signs. Retrieved November from http://www.amazon.co.uk.

Dadzie, J. (2013). Perspectives of consultants on health and safety provisions in the labor act: a study into theory and practicals. Engineering Management Research, 2(1), 34.

Danso, F. (2005). Improving safety on building construction site on KNUST campus in Kumasi, Ghana. (Unpublished BSc Thesis, Faculty of Architecture and Building Technology). KNUST, Kumasi, Ghana.

General Organization for Social Insurance (GOSI) (2015). Annual Statistical Report 1435h: General Organization for Social Insurance (GOSI).

Greuter, S., Tepe, S., Peterson, J. F., Boukamp, F., Amazing, K. D., Quigley, K. \& Wakefield, R. (2012). Designing a Game for Occupational Health and Safety in the Construction Industry. Australian Construction Management, ACM IE '12, July 21 - 22 2012, Auckland, NZ, New Zealand. DOI: 10.1145/2336727.2336740.

Hare, B., Cameron, I., Real, K. J. \& Maloney, W. F. (2012). Exploratory case study of pictorial aids For communicating health and safety for migrant construction workers. Journal of Construction Engineering and Management, 139(7), 818-825.

Henley, M., Keddy, M., Kinsman, B., Muggridge, M. \& Shields, K. (2015). Semiotic Analysis: A Research Guide. Retrieved March 3, 2018, from Imogen Charles http://fr.scribd. com;presentations.

Huhtamo, E. (2003). Visual Communication and Semiotics. DESMA 103 Visual Communication Spring, Retrieved June 12, 2017 from http://www.erkkihuhtamo.com.

International Labour Organisation-ILO (28 April, 2017). One Worker Dies Every 15 Seconds, 153 Have Work-Related Accidents, 2017 World Day For Safety And Health At Work In Abuja, Vanguard Nigeria.

Inuwa, I. I. (2014). Project Planning In Construction Procurement: The Case of Nigerian 
Indigenous Contractor. ( $\mathrm{PhD}$ Thesis), Jomo Kenyatta University of Agriculture and Technology, Nairobi-Kenya.

Inuwa, I. I., Alara, S. A. \& Gambo, N. (2018). Health and safety awareness on construction sites in Yola Metropolis of Nigeria. Paper presented at the International Conference on Contemporary Issues In Business \& Economics (ICCIBE), Tasliciftlik Campus, Gaziosmanpasa University, Tokat, Turkey. 235-244.

Kasimu, A. \& Usman, M. (2013). Delay in Nigerian construction industry. Journal of Environmental Sciences and Resources Management, 5(2), 120-129.

Kometa, S. T., Olomolaiye, P. O. \& Harris, F. C. (1994). Attributes of UK construction clients influencing project consultants' performance. Construction Management and economics, $12(5), 433-443$.

Kwofie, E. T. (2015). Contribution of unique features of mass housing projects to project team communication performance ( $\mathrm{PhD}$ Thesis, College of Art and Built Environment). KNUST, Kumasi, Ghana.

Landin, E. \& Kindahl, N. (2013). Information and communication trends in the Swedish construction industry. (Msc Thesis, Department of Real Estate and Construction Management). KTH Sweden.

Laryea, S. \& Mensah, S. (2010). Health and Safety on Construction Sites in Ghanall in The Construction, Building and Real Estate Research Conference of the Royal Institution of Chartered Surveyors, 2-3 September 2010, Dauphine Universite, Paris, France.

McKenzie, J., Gibb, A. G. F. \& Bouchlaghem, N. M. (1999). Communication of Health and Safety in Design Phase: Implementation of Safety and Health on Construction Sites. Paper presented at the Proceedings of the 2nd International Conference of International Council for Research and Innovation in Building and Construction (CIB) Working Commission W99, Honolulu.

Md-Ulang, N. (2012). Communication of construction health and safety information in design.C Norhidayah Md Ulang.

Ogunmola, A. A. (2013). Signs and Symbols as Communication Strategy: A Semiotic Study of Highway Codes in Nigeria. Journal of New Media and Mass Communication, 19(1), 62-68.

Olaniran, H. (2015). On the role of communication in construction projects in Nigeria. Journal of Environmental Science and Technology, 2(5), 048-054.

Olatunji, O. A., Aje, O. I. \& Odugboye, F. (2007). Evaluating Health and Safety Performance of Nigerian Construction Site. Paper presented at the CIB World Building Congress, 2007.

Pallant, J. (2011). SPSS Survival Manual: A Step by Step to Data Analysis Using SPSS. New South Wales: Allen \& Unwin.

Phoya, S. (2012). Health And Safety Risk Management on Building Construction Sites in Tanzania: The Practice of Risk Assessment, Communication and Control (Licentiate thesis, Chalmers University of Technology), Gothenburg, Sweden.

Preece, C. \& Stocking, S. (1999). Safety Communications Management In Construction Contracting. Paper presented at the Hughes, W, 15th Annual ARCOM Conference, Liverpool John Moores University.

Tipli, L. G, Ojeba, P. O. \& liyasu, M. S. (2014). Evaluating the effects of communication in construction project delivery in Nigeria. Global Journal of Environmental Science and Technology, 2(5): 048-054.

Umeokafor, N., Isaac, D., Jones, K. \& Umeadi, B. (2014). Enforcement of occupational safety 
and health regulations in Nigeria: An exploration. European Scientific Journal, 3, 93-104.

Vecchio-Sadus, A. M. (2007). Enhancing safety culture through effective communication. Safety Science Monitor, 11(3), 1-10.

Windapo, A. O. (2013). Relationship between degree of risk, cost and level of compliance to occupational health and safety regulations in construction. Construction Economics and Building, 13(2), 67-82. 